\title{
INDICADORES DE POBREZA NAS POLÍTICAS SOCIAIS BRASILEIRAS
}

\author{
Ana Paula Ornellas Mauriel \\ Universidade Federal Fluminense (UFF) \\ Caroline Beatriz Rangel Rais \\ Marinha do Brasil
}

\section{INDICADORES DE POBREZA NAS POLÍTICAS SOCIAIS BRASILEIRAS}

Resumo: O objetivo central do texto é demonstrar como o uso (e abuso) dos indicadores sociais na formulação de políticas sociais, particularmente os que se referem à pobreza, tem sido estratégico para reorganização do padrão de proteção social brasileiro, no sentido de afirmar a garantia do mínimo como patamar oficial e fundamentar um novo consenso em torno do significado de universalidade. Para fundamentar tal consenso cognitivo e normativo, a centralização nos aspectos individuais e as referências locais passam a imperar como princípios organizativos das ações para expansão da cobertura dos esquemas não contributivos.

Palavras-chave: Indicadores sociais, política social, pobreza, universalidade.

\section{POVERTY INDICATORS IN BRAZILIAN SOCIAL POLICIES}

Abstract: The text's main objective is to show how the use (and abuse) of social indicators in the formulation of social policies, particularly those related to poverty, has been strategic to the reorganization of Brazilian's social protection pattern, by affirming the guarantee of the minimum as official government policy and enhancing a new consensus around the meaning of universality. To build on this cognitive and normative consensus, the centralization in individual aspects and local references start to reign as organizational principles of actions to the expansion of non-contributive schemes' coverture.

Key words: Social indicators, social policy, poverty, universality. 


\section{INTRODUÇÃO}

"Sob a pele das palavras há cifras e códigos.

O sol consola os doentes e não os renova. As coisas. Que tristes são as coisas, consideradas sem ênfase."

(Carlos Drummond de Andrade, A Flor e a Náusea)

O desenvolvimento de indicadores sociais no Brasil é considerado por muitos autores como fenômeno recente (JANNUZZI, 2003), datando dos anos 1960, contexto de ditadura militar. $\mathrm{Na}$ ocasião, o objetivo de instauração de uma tecnocracia, com a utilização de indicadores sócio-econômicos, obedecia aos princípios antidemocráticos de controle político e serviam para legitimar ações arbitrárias por parte do executivo federal (VIANNA, 1998).

A diversificação e proliferação do uso de indicadores estão ligadas às reformas estruturais liberalizantes conduzidas nos anos 1990, quando os Mapas da Fome, divulgados pelo IPEA, deram a partida para a elaboração de indicadores que tivessem como referência os municípios ${ }^{1}$. A partir daí a tendência do uso de indicadores dos mais variados tipos para formulação de políticas sociais só aumentou. E, embora o universo de indicadores sociais seja vasto (JANNUZZI, 2003), a tendência tem sido priorizar os indicadores de pobreza como principais referências para formulação, gestão e avaliação das políticas sociais.

A despeito das críticas e das tentativas de incorporar a multidimensionalidade da pobreza, e mesmo considerando as variações metodológicas, os cálculos ainda consideram a renda como principal referência para indicar o nível de miséria (PEREIRA; AMORIM, 2010; DORNELLES, 2007; SOARES, 2004). Nesse cenário, o Índice de Desenvolvimento Humano vem sendo saudado como principal saída para essa visão restrita de pobreza, ao incorporar outras dimensões - saúde e educação - para além da renda, embora não abandone essa referência.

A construção de parâmetros definidores dos mínimos sociais, contudo, não se resume à engenharia técnica e à mágica matemática das metodologias dos cálculos, pois a produção dos indicadores sociais é ao mesmo tempo ética e política (TELLES, 2003). Por trás dos índices e medidas há uma intensa batalha de ideias que conforma um tortuoso, e quase sempre conflituoso, processo de construção das políticas públicas.

Assim,

[...] os indicadores não medem a realidade, algo que estaria lá, pronto para ser descrito; mas participam da construção social da realidade. (TELLES, 2003, p. 4, grifo nosso).
Por meio de um transformismo político conseguido a partir da celebração do alívio da pobreza direcionado ao imenso contingente de trabalhadores precários, as principais instituições difusoras do liberalismo social vêm reificando o indivíduo e fortalecendo as medidas sociais com base em micronichos (LEHER, 2010) como referência para as reformas na proteção social.

O complexo caminho de reforma do sistema de proteção social brasileiro, nas duas últimas décadas, conjuga múltiplas determinações internacionais, nacionais e locais, pautado por uma diversificada gramática na produção de evidências e referências que orientam o debate público para longe da ideia de universalidade, tal como se fez presente na concepção socialdemocrata e beveridgiana de proteção social.

Os eixos dessa renovada concepção de proteção social colocam a relação entre focalização e universalização em outro patamar, não mais antagônico, mas de conjugação das duas tendências, aliando as reformas previdenciárias a um conjunto de ações difusas classificadas como "proteção não contributiva". Tal hibridismo não caracteriza apenas uma tentativa de expandir o mercado de seguros sociais, mas de "assistencializar" a Seguridade, o que é denominado por Vianna (2010) de "novo universalismo"2.

É diante dessas questões que se propõe pensar o papel dos indicadores sociais, particularmente os de pobreza, na formulação das políticas sociais como recurso estratégico para reorganização do padrão de proteção social brasileiro, no sentido de afirmar a garantia do mínimo absoluto como patamar oficial das ações sociais e fundamentar um novo consenso em torno do significado de universalidade.

Para fundamentar as assertivas acima mencionadas, a exposição parte de alguns antecedentes históricos dos indicadores de pobreza e sua relação com as dimensões econômica e política. Em seguida, volta-se para a caracterização dos principais indicadores de pobreza no contexto contemporâneo e seu papel na conformação de consensos em torno do que são (ou deveriam ser) os mínimos sociais e sua relação com a efetivação de direitos sociais.

\section{DE ONDE VEM A LINHA DA POBREZA E PARA ONDE VÃO AS POLÍTICAS SOCIAIS?}

Alan Gillie ${ }^{3}$ (1996 apud MAURIEL, 2011) mostra que o conceito de "linha de pobreza" remonta ao final do século XIX, na Inglaterra. Segundo o autor, a origem oficial é tida como mérito de Charles Booth, que embora não tenha utilizado o termo "linha de pobreza" para denominar a divisão entre pobres e não pobres, passou a ser conhecido pelo trabalho de Rowntree, de 
$1902^{4}$, que utilizava como referência aquilo que classificou como a "linha de pobreza" de Booth.

Mas, no desenrolar do artigo, Gillie mostra como esse conceito já era uma prática social quando Booth o tomou. As somas e medidas referentes que aparecem no texto de Booth não foram criadas por ele, mas decalcados de medidas anteriores ligadas às instituições vinculadas às Leis dos Pobres. Em 1870, embora as autoridades das Poor Laws já perdessem terreno, - Elementary Education Act convidou as escolas a desenvolverem um critério de pobreza para identificar quem receberia subsídios do Estado para nelas manter as crianças.

Após a eleição, em 1871, dos membros do Conselho das Escolas de Londres, criouse um comitê para implementar as provisões estabelecidas na seção 74 do Ato Elementar de Educação de 1870. Assim, pais que foram requeridos a enviar crianças entre 5 e 13 anos para a escola não poderiam apresentar a pobreza como desculpa para o descumprimento da lei, de modo que as escolas não tardaram em desenvolver diversas "linhas de pobreza", algumas mais famosas baseadas na renda por pessoa, outras nas condições de moradia ou até mesmo na qualidade da alimentação dos integrantes das famílias (GILLIE, 1996 apud MAURIEL, 2011).

As descobertas de Booth tocam questões contemporâneas da pobreza e mitos que o conhecimento contemporâneo sobre o tema procura disseminar. Ele e seus assistentes construíram mapas com uma ilustração da geografia da pobreza e da riqueza na Inglaterra, com grande parte das suas revelações estatísticas reproduzidas por pesquisadores americanos para investigar a situação nos Estados Unidos. Esses mapas inspiraram a criação de uma geração de investigadores americanos cuja preocupação era observar e cadastrar a vida dos pobres.

A linha de pobreza caracteriza-se como exemplo de iniciativa que se generalizou tomando como referência necessidades localizadas, cuja consequência imediata foi, acima de tudo, o desenvolvimento futuro do conhecimento sobre pobreza como um campo científico de pesquisa social empírica, informando sobre condições sociais de vida dos pobres, deslocando a agenda de debate constituída ao longo do século XIX em torno do pauperismo ${ }^{5}$, cujas referências estavam mais ligadas às causas da pobreza do que propriamente à caracterização do fenômeno.

As variações nas práticas de combate à pobreza normalmente refletem os vestígios de influência das Poor Laws inglesas, que se baseavam em alguns princípios-chave, como o da responsabilidade local, o da menor elegibilidade, e o da fixação territorial.

Tais princípios subjazem os sistemas assistenciais contemporâneos, e não devem ser vistos apenas como meros vestígios de uma tradição arcaica, pois possuem uma importante função na dinâmica econômica contemporânea, qual seja, tornar possível moldar as práticas de assistência de acordo com diferenças nas práticas de trabalho entre regiões, estados e localidades (e até entre países e continentes inteiros, na realidade assimétrica da ordem econômica mundial contemporânea), tornando o esquema de proteção social altamente flexível.

O princípio da responsabilidade local assegura que os órgãos oficiais possam criar critérios variados de elegibilidade para melhor atender aos diferentes requerimentos do uso do trabalho. A regra da menor elegibilidade assegura que os benefícios de bem-estar não se tornem competitivos com os salários, não importa o quanto os salários abaixem, pois os benefícios sempre se ajustam, ao passo que, as leis que se referem à fixação de residência local garantem que esses arranjos se firmem em dados lugares, asseverando que as variações nas práticas de alívio podem ser entendidas pelas funções econômicas que possuem.

É importante notar como o "princípio da fixação" reforça as funções econômicas dos de menor elegibilidade e responsabilidade local, sendo, pois, interligados. Com efeito, as leis relativas à fixação de residência normalmente resultavam na negação de assistência para os que não viviam há determinado tempo (geralmente um critério de elegibilidade) no local. Isso acaba por aprofundar o relacionamento entre o sistema de bem-estar regional e a economia regional, ligando os pobres aos salários locais e às restrições, também locais de bem-estar, a fim de que, se tentarem se mover de um lugar ao outro em busca de melhores empregos, não sejam elegíveis pela assistência pública ${ }^{6}$.

Assim, o encaixe do sistema de bem-estar numa economia capitalista, embora com alto grau de diversidade, é assegurado pela variedade dos critérios de acesso, em acordo com as diferenças regionais e locais dos requisitos (do uso da força) de trabalho. Atualmente, as ações de combate à pobreza são prioritariamente direcionadas àqueles que permanecem no mercado de trabalho com vínculos informais, precários e mal-pagos, mesmo que atinjam também os incapacitados parcial ou inteiramente, temporária ou permanentemente (MAURIEL, 2011).

\section{INDICADORES DE POBREZA NO CENÁRIO CONTEMPORÂNEO: a perspectiva do} desenvolvimento humano

Atualmente, a mensuração por "linhas de pobreza" ainda se mantém como forte tendência na mensuração de pobres no âmbito internacional e no Brasil, a despeito da concepção restritiva que 
as embasa - o corte de renda. Os critérios vão desde variações do salário mínimo, passam por padrões monetários internacionais, como o dólar per capita ao dia, chegando até valores suficientes (ou não) para adquirir uma cesta básica de alimentos (nesse caso, a referência é considerada como "linha de indigência" pela CEPAL).

Os cálculos são variados e trazem grandes divergências a depender da metodologia empregada. No Brasil, "o número de extremamente pobres varia, nos dias atuais, entre 10 e 50 milhões, dependendo da linha utilizada" (PEREIRA; AMORIM, 2010, p. 137). Essa variação, pelas consequências sociais que pode gerar, configura um grave problema político: qual recorte deve prevalecer?

[...] um recorte alto demais acaba não indicando quem são os realmente pobres e, por outro lado, um recorte muito baixo, deixaria de fora grupos sociais necessitados de proteção pública [...] Em outras palavras, a questão da definição da linha, que em um primeiro momento parecia um problema técnico, se transforma em um problema político. (PEREIRA; AMORIM, 2010, p. 138)

$\mathrm{Na}$ tentativa de superar essa medida de corte considerada arbitrária, diversas tentativas de incorporar outros critérios além da renda vêm levando à construção de indicadores capazes de dar conta da complexidade das situações de precariedade em que grandes segmentos populacionais se encontram. O exemplo mais conhecido e utilizado é o Índice de Desenvolvimento Humano (IDH) e seus desdobramentos posteriores.

O IDH foi criado, em 1990, pelos economistas Amartya Sem (2000) e Mahbub UI Haq (1995), e desde então passou a ser usado pelo Programa das Nações Unidas para o Desenvolvimento (PNUD) nos seus Relatórios Anuais. Na ocasião em que foi criado, apresentava três indicadores, com suas respectivas variáveis: saúde (esperança de vida), educação (taxas de escolarização e alfabetização de adultos) e renda (PIB per capita junto a técnica que reflete os recursos necessários para comprar bens e serviços que garantam a sobrevivência). Suas medidas situamse entre 0 e 1 , o que classifica os países entre baixo $(-0,5)$, médio $(0,5-0,8)$ e alto $(0,8-1,0)$ nível de desenvolvimento humano. Jannuzzi (2003) salienta que a saúde e a educação passaram a ser suas dimensões agregadas à renda porque eram as que dispunham de maior regularidade de informações ${ }^{8}$.

O Programa das Nações Unidas para o Desenvolvimento (PNUD) teve um papel fundamental para o surgimento de outros indicadores sob a ótica do "Desenvolvimento
Humano", com objetivo de medir o grau de êxito no atendimento às necessidades humanas. Além do IDH, oito indicadores sociais foram criados por esse órgão ao longo das duas últimas décadas: a) Índice de Desenvolvimento Humano (já explicitado); b) Índice de Liberdade Humana9; c) Índice de Liberdade Política ${ }^{10}$; d) Índice de Desenvolvimento Ajustado ao Sexo (foi substituído pelo Índice de Desenvolvimento por Gênero) ${ }^{11}$; e) Medida de Participação Ajustada ao Sexo (cedeu espaço para o Índice de Poder por Gênero)12; f) Medida de Privação de Capacidade; e g) Índice de Pobreza Humana.

No último Relatório de Desenvolvimento Humano, referente ao ano de 2010, é elucidado que os resultados do IDH, aplicado em 169 países, não podem ser comparados com os dados de relatórios anteriores, pois o cálculo deste índice sofreu aperfeiçoamentos metodológicos. Suas três dimensões iniciais foram mantidas, porém os cálculos das variáveis de educação e renda foram alterados. No primeiro, a taxa de matrículas brutas cedeu lugar para a expectativa de anos de escolaridade para as crianças em idade escolar, assim como a taxa de alfabetização de adultos foi substituída pela média de anos de escolaridade da população adulta. Já no segundo, o PIB per capita trocado pelo chamado Rendimento Nacional Bruto per capita ${ }^{13}$. A esperança de vida se manteve como principal indicador de saúde.

Apesar das alterações, os valores do IDH permaneceram na escala de 0 a 1 , mas com uma classificação modificada para: muito elevado, elevado, médio e baixo. Além disso, - Relatório de Desenvolvimento Humano de 2010 traz três novos indicadores sintéticos ${ }^{14}$ : o Índice de Desenvolvimento Humano Ajustado à Desigualdade (IDHAD) ${ }^{15}$, o Índice de Desigualdade de Gênero (IDG) ${ }^{16}$ e o Índice de Pobreza Multidimensional (IPM).

O Índice de Pobreza Multidimensional (IPM) atua na perspectiva de identificar privações nas mesmas dimensões do IDH e revela a quantidade de pessoas pobres ${ }^{17}$ e de privações com que as famílias consideradas pobres geralmente convivem. Esta mensuração substitui o pioneiro Índice de Pobreza Humana (IPH), criado em $1997^{18}$. Segundo o IPM, uma família é considerada pobre em termos multidimensionais se tiver privações entre dois e seis indicadores. As dimensões que o IPM contempla são parecidas com a do IDH - saúde, educação e padrões de vida - e todas juntas envolvem dez indicadores no total. $O$ valor desse índice no caso brasileiro é de 0,039, com $8,5 \%$ de quantidade de pobres em relação à população e $46,0 \%$ de intensidade de privação.

Para visualização dos índices e suas respectivas definições, seguem os quadros ao lado: 
QUADRO 1 - Síntese dos principais indicadores de pobreza

\begin{tabular}{|c|c|c|c|}
\hline $\begin{array}{l}\text { INDICADORES } \\
\text { SINTÉTICOS - PNUD }\end{array}$ & $\begin{array}{l}\text { ANO DE } \\
\text { CRIAÇÃO }\end{array}$ & $\begin{array}{l}\text { ANO DE EXTINÇÃO } \\
\text { E/OU } \\
\text { SUBSTITUIÇÃO }\end{array}$ & DEFINIÇÃO \\
\hline $\begin{array}{l}\text { Índice de Desenvolvimento } \\
\text { Humano (IDH) }\end{array}$ & 1990 & - & $\begin{array}{l}\text { Mensuram o grau de desenvolvimento } \\
\text { econômico e a qualidade de vida oferecida à } \\
\text { população. }\end{array}$ \\
\hline $\begin{array}{l}\text { Índice de Liberdade } \\
\text { Humana (ILH) }\end{array}$ & 1991 & - & $\begin{array}{l}\text { Mede o grau de liberdade dos povos com } \\
\text { base em convenções internacionais e na De- } \\
\text { claração Universal dos Direitos Humanos. }\end{array}$ \\
\hline $\begin{array}{l}\text { Índice de Liberdade Política } \\
\text { (ILP) }\end{array}$ & 1992 & - & $\begin{array}{l}\text { Formam indicadores a fim de avaliar o atendi- } \\
\text { mento (ou não) de direitos. }\end{array}$ \\
\hline $\begin{array}{l}\text { Índice de Desenvolvimento } \\
\text { Ajustado ao Sexo (IDS) }\end{array}$ & 1995 & 1997 & \multirow{2}{*}{$\begin{array}{l}\text { Aponta diferenças entre esperança de vida, } \\
\text { alfabetização, matrícula na escola e renda } \\
\text { entre homens e mulheres. }\end{array}$} \\
\hline $\begin{array}{l}\text { Índice de Desenvolvimento } \\
\text { por Gênero (IDG) }\end{array}$ & 1997 & - & \\
\hline $\begin{array}{c}\text { Medida de Participação } \\
\text { Ajustada ao Sexo (MPAS) }\end{array}$ & 1995 & 1997 & \multirow{2}{*}{$\begin{array}{l}\text { Tem por objetivo mensurar o nível de par- } \\
\text { ticipação das mulheres como mão de obra } \\
\text { em cargos altos, na política e em profissões } \\
\text { técnicas. }\end{array}$} \\
\hline $\begin{array}{l}\text { Índice de Poder por Gênero } \\
\text { (IPG) }\end{array}$ & 1997 & - & \\
\hline $\begin{array}{l}\text { Medida de Privação de } \\
\text { Capacidades (MPC) }\end{array}$ & 1996 & 1997 & $\begin{array}{l}\text { Considera a falta de } 3 \text { capacidades: de estar } \\
\text { bem alimentado, de se reproduzir de um } \\
\text { modo saudável e de ser educado e instruído. }\end{array}$ \\
\hline $\begin{array}{l}\text { Índice de Pobreza Humana } \\
\text { (IPH) }\end{array}$ & 1997 & 2010 & $\begin{array}{l}\text { Representa as dimensões de carência da vida } \\
\text { humana, focando a amplitude da miséria nos } \\
\text { países considerados pobres. }\end{array}$ \\
\hline
\end{tabular}

Fonte: Elaboração própria com base nos relatórios do PNUD.

QUADRO 2 - Novos índices do PNUD em 2010

\begin{tabular}{|c|c|l|}
\hline $\begin{array}{c}\text { INDICADORES } \\
\text { SINTÉTICOS - PNUD }\end{array}$ & $\begin{array}{c}\text { ANO DE } \\
\text { CRIAÇÃO }\end{array}$ & \multicolumn{1}{|c|}{ DEFINIÇÃO } \\
\hline $\begin{array}{c}\text { Índice de Desenvolvimento } \\
\text { Humano Ajustado à } \\
\text { Desigualdade (IDHAD) }\end{array}$ & 2010 & $\begin{array}{l}\text { Visa identificar as respectivas perdas no desenvolvimento } \\
\text { humano como consequência de desigualdades nas dimensões } \\
\text { de saúde, educação e rendimento. }\end{array}$ \\
\hline $\begin{array}{c}\text { Índice de Desigualdade de } \\
\text { Gênero (IDG) }\end{array}$ & 2010 & $\begin{array}{l}\text { Mensura os pontos negativos do desenvolvimento humano de } \\
\text { discrepâncias sociais e econômicas acentuadas entre mul- } \\
\text { heres e homens. }\end{array}$ \\
\hline $\begin{array}{c}\text { Índice de Pobreza } \\
\text { Multidimensional (IPM) }\end{array}$ & 2010 & $\begin{array}{l}\text { Identifica privações nas mesmas dimensões do IDH e revela a } \\
\text { quantidade de pessoas na pobreza e de privações com que as } \\
\text { famílias consideradas pobres geralmente convivem. }\end{array}$ \\
\hline
\end{tabular}

Fonte: Elaboração própria a partir de relatório do PNUD (2010).

O Brasil se insere no ranking do PNUD com IDH médio entre 1999 e 2009. A partir de 2010, quando foi adotada outra metodologia do IDH, o Brasil aparece posicionado em $73^{\circ}$ lugar, com um valor de 0,699, considerado na classificação de IDH elevado ${ }^{19}$. Já segundo cálculos do IPM, O Brasil tem cerca de $13,1 \%$ de sua população na pobreza multidimensional, no período de 2000 a 2008.

O PNUD tem patrocinado o cálculo do IDH em estados e municípios, como foi feito no Brasil pelo Instituto de Pesquisa de Economia Aplicada (IPEA) e pela Fundação João Pinheiro em 1996, dando origem ao Índice de Desenvolvimento
Humano em escala Municipal (IDH-M). Este contém os mesmos indicadores do IDH primário $^{20}$, mas com a preocupação em aprimorar os cálculos e mensuração das dimensões renda e educação. Por isso, utilizaram como referência a renda municipal per capita ao invés da renda familiar per capita média nacional, e a quantidade média de anos de estudo da população adulta - pessoas com 25 anos ou mais - foi substituída pela taxa bruta de comparecimento à escola.

Depois da criação do IDH-M, a Fundação João Pinheiro criou o Índice de Condições de Vida (ICV), que acompanhava o desenvolvimento humano e 
as condições de vida nos municípios a partir de 16 indicadores. No Rio de Janeiro, a Fundação CIDE elaborou o Índice de Qualidade Municipal (IQM) com o objetivo de conhecer melhor a realidade fluminense e contou com o financiamento da Fundação Carlos Chagas Filho de Amparo à Pesquisa do Estado do Rio de Janeiro (FAPERJ).

O Instituto Brasileiro de Geografia e Estatística (IBGE) tem como principais produtos: o Censo Demográfico (que se realiza de 10 em 10 anos) e a Pesquisa Nacional por Amostra de Domicílios (PNAD), além de atualizar os dados obtidos pelo Censo Demográfico no que diz respeito aos Estados e às principais regiões metropolitanas. A partir desse conjunto de dados, o IBGE produz a Pesquisa de Informações Básicas Municipais (MUNIC), com o objetivo de analisar vários aspectos ligados ao desenvolvimento regional, a gestão e o planejamento municipal.

Contudo, não só o IBGE elabora estudos para a criação de indicadores sociais municipais, são relevantes também os dados disponibilizados por vários Ministérios na Internet, tanto a partir de temas como pela escala territorial. Uma iniciativa de grande relevância foi a elaboração do Índice de Desenvolvimento da Família (IDF), conceituado como um indicador que possibilitará aos gestores locais realizar um mapeamento que identifique as vulnerabilidades e potencialidades das famílias nos municípios para que, dessa forma, seja viável atuar sobre elas. Esse índice abarca valores que variam entre 0 (quando a situação familiar é ruim) e 1 (quando a família se encontra na melhor situação possível). Sem incluir indicadores referentes à saúde, o IDF apresenta 6 dimensões ${ }^{21}$, subdivididas entre a satisfação de necessidades das famílias e a efetivação dessas necessidades.

Todos esses índices e composições de mensuração, embora com metodologias distintas, preocupam-se em estabelecer patamares mínimos de sobrevivência, ainda que com certa margem de variação para cima ou para baixo.

\section{A DEFINIÇÃO DO MÍNIMO COMO PATAMAR OFICIAL}

A preocupação com a identificação e mensuração dos pobres no contexto contemporâneo vem atrelada à justificativa de maior eficiência nos gastos sociais, como parte do conjunto de reformas que pressionaram os governos dos países periféricos a tomar medidas com vistas à desoneração dos gastos públicos, particularmente os gastos sociais. Diante disso, a focalização, ou o foco nos mais pobres, aparece como resposta engenhosa para a alegada escassez de recursos públicos, pois conseguiria diminuir as pressões dos segmentos classificados como "excluídos" e "vulneráveis" sem necessariamente tornar onerosos os gastos sociais (MACHADO, 2006; SOUZA; CARNEIRO, 2007).
Santagada (2007) observa que os objetivos dos governos se articulam com os indicadores recrutados para concepção e gestão de políticas e programas, e geralmente com o sentido de controlar as concepções de bem-estar e qualidade de vida que circunscrevem o horizonte do debate sobre política social. É sob essa perspectiva que ocorre a elaboração de indicadores de bem-estar sintéticos e o desenvolvimento de relatórios sociais prospectivos e normativos, criando uma objetivação de situações e circunscrição de áreas geográficas, cujos significados são mais artificiais que reais.

No mesmo sentido argumentam Pereira e Amorim (2010, p. 138), afirmando que "as linhas oficiais de pobreza tendem a se transformar numa espécie de ficção estatística que passa a ter vida própria, com relações muitas vezes remotas da realidade", mas com impactos importantes na condução das políticas públicas.

Jannuzzi (2003) salienta que há uma tendência cada vez maior de identificar um determinado conceito com as medidas necessárias para mensurá-lo, como se estas representassem exatamente o conceito. Assim, as medições referentes a conceitos pré-estabelecidos passam a ser vistas como um retrato fidedigno da realidade, acarretando a redução do conceito às dimensões expressas pelos indicadores, levando à banalização de concepções. Diante da subjugação do conceito à medida, como se esta fosse a representação exata da realidade, há ocorrências de que, muitas vezes, a medida é criada para que depois seja encaixado o conceito mais adequado (JANNUZZI, 2002).

É preciso reconhecer que tais índices ganharam profunda legitimidade em várias dimensões da sociedade, principalmente na mídia, alguns movimentos sociais e ONG's que atuam politicamente no acompanhamento de políticas e programas sociais. Além disso, muitos indicadores foram encomendados por gestores e legisladores, que, ao apontar suas intenções e expectativas, já asseguram sua legitimidade técnica. Como desdobramento, tem-se o financiamento dos mais variados projetos para formulação de indicadores por agências de pesquisa nacionais e internacionais, garantindo legitimidade científica. $E$, na medida em que tais medições ganham operacionalidade institucional e participam do processo de tomada de decisões públicas, mantém ativa a funcionalidade de um mercado de indicadores (JANNUZZI, 2005).

É nesse sentido que apontamos que a razão instrumental participa da construção de consensos cognitivos, entendidos como "certezas e evidências sobre as coisas em torno das quais o debate se desenvolve", numa tripla dimensão: descritiva/ cognitiva, normativa/prescritiva e política, na medida em que circunscreve arenas políticas e o jogo dos atores e operadores políticos (TELLES, 2003, p. 1). 
Com o processo de descentralização das políticas públicas no Brasil, os municípios se viram desafiados a construir planejamentos locais, realizar diagnósticos acerca de determinados territórios, como condição para o repasse de verbas e gestão e avaliação de políticas e programas sociais. Nesse contexto, se acirra a preocupação com o acompanhamento local, com foco nos bairros mais atingidos pela pobreza e falta de infra-estrutura (GUIMARÃES; JANNUZZI, 2004).

A partir daí, um vocabulário variado passou a compor as iniciativas municipais: "participação de moradores", "projetos locais", "proximidade", "transversalidade", "deliberação entre parceiros", "territorialidade", entre outros termos, cujo tom humanista e progressista os tornam difíceis de questionar. Os novos profissionais do desenvolvimento social (e humano), formados dentro dos horizontes indicados pelos thinkthanks internacionais, explicam como transformar reivindicações populares em proposições e pedidos de assistência, que retornam como projetos de "empoderamento" e capacitação dos moradores, configurados em intervenções individualizantes e responsabilizantes da própria população e da "comunidade" (TISSOT, 2007).

Os governos municipais passaram, então, a adotar medidas de gestão e referências que ajudam a especializar cada vez mais o enfrentamento das expressões da questão social, cujo efeito é tornar invisível a relação entre a situação dos bairros estatisticamente "mais pobres" e o que se passa nos universos mais amplos da vida social, particularmente no mundo do trabalho.

As novas realidades urbanas apresentam formatos plurais e desconcentrados que desafiam a montagem de novas referências, cuja tendência tem sido olhar com mais acuidade as disparidades locais (TELLES, 2003). Vale alertar, contudo, que

[...] é importante identificar as ambivalências contidas nos microdados e micro-referências. Há sempre o risco de sua captura nas novas formas de gestão da pobreza, desconectadas de políticas capazes de interferir nos processos estruturantes que engendram novas desigualdades e novas clivagens sociais hoje estampadas nos cenários urbanos (TELLES, 2003, p. 7)

A preocupação em medir e classificar as disparidades e situações vivenciais dos indivíduos, famílias ou mesmo comunidades, aumentou com a implementação do Sistema Único de Assistência (SUAS), que traz como um de seus princípios organizativos a territorialidade. $O$ mapeamento das realidades locais revela não só uma "geografia da pobreza", mas a diversidade de situações de precariedade consequentes dos processos contemporâneos de expropriação, o que é classificado, no caso das cidades, como "periferias" (SOARES, 2004).

O território pode ser um potencial eixo integrador de políticas sociais, mas não como está pautado no discurso do desenvolvimento humano e da governança local ${ }^{22}$, que vem ajudando mais na fragmentação espacial das cidades do que em sua composição numa perspectiva de totalidade. Quando se coloca no centro da discussão a capacidade dos indivíduos para transformar bens e recursos em formas de vida com qualidade e bem-estar (SEN, 2010), centra-se exclusivamente a responsabilidade pelo "desenvolvimento local" nas pessoas, ocultando que as condições materiais de vida dos moradores e da comunidade são resultantes de processos mais amplos de subalternização e precarização construídos historicamente e reforçados pelos programas de ajustes ortodoxos, pelo menos quando se considera as "periferias" brasileiras.

[...] a pobreza vem sendo apresentada mais como uma questão psicológica e local, e os indivíduos por ela afetados são convidados a transformar a si mesmos, em vez de se apontar o dedo para os mecanismos estruturais que os condicionam (TISSOT, 2007, p.30)

Se as referências para avaliar e formular políticas e programas são estritamente o que as pessoas conseguem ser e fazer em seus bairros e a liberdade de escolherem vários modos de viver a partir do local onde se encontram, os indicadores serão formulados no sentido de avaliar em que medida as políticas sociais são ou não meios eficazes para que as próprias pessoas (ou comunidades) possam converter bens e rendas em "efetivações" e "realizações" locais.

Sob essa perspectiva, abre-se um universo infinito de possibilidades de formulação de indicadores, índices e mapas que busquem mostrar as condições de acesso a diversos espaços, serviços, bens materiais e simbólicos e seus usos, mas sempre reforçando o mínimo como o desejável, como alcançável, como possível. Cabe ressaltar, ainda, que a noção de acesso aparece reeditada, pois significa acesso à possibilidade - à vara de pescar e como utilizá-la - mas sem garantia de que o resultado (o peixe) será alcançado (pescado ou se chegará por algum outro meio mais empreendedor).

\section{CONCLUSÃO}

"O que se pode medir é solucionável", afirmou o diretor da Coca-Cola, tal qual registrado no Relatório de Desenvolvimento Humano de 
2000. Tal assertiva introduz o documento que vê os indicadores como poderosos instrumentos para a promoção dos direitos humanos e afirma que têm o poder de estabelecer prioridades e padrões de referência, asseverando que as estatísticas se tornaram a área mais avançada na defesa de várias questões sociais e ambientais e podem ajudar a modificar percepções, políticas públicas e práticas sociais (PROGRAMA DAS NAÇÕES UNIDAS PARA O DESENVOLVIMENTO, 2000).

Do poder dos indicadores não discordamos, mas não os consideramos suficientes para construção de qualquer solução pública para problemas coletivos. Ao longo do texto procurouse demonstrar, justamente que, desde sua origem, para além de um problema técnico, subjazem aos indicadores opções éticas, políticas e teóricas. E que a depender da perspectiva teórica prevalecente - no caso a de Desenvolvimento Humano - os indicadores realmente possuem o poder de definir prioridades e ações. Mas quais as prioridades hoje?

A tendência central desde meados dos anos 1990 tem sido o reforço de iniciativas compensatórias com base em um assistencialismo precário que elege determinadas "clientelas" como alvo de atenção. A focalização foi, durante os anos 1990 e primeira metade dos anos 2000, uma resposta engenhosa para a alegação da suposta escassez de recursos públicos, mas não constitui em si uma alternativa para o equacionamento dos graves problemas da realidade brasileira e compromete a garantia das condições de efetivação dos direitos sociais, normalmente atrelados ao princípio de universalização.

A focalização, como justificativa para maior eficiência dos gastos, tem seu maior paradoxo na desvinculação da ideia de direito social. $E$ foi justamente na tentativa de superar tal contradição que se parte para "[...] uma rediscussão da escolha entre universalização e focalização." (VIANNA, 2010, p. 38). O que se apresenta não é mais uma contraposição entre focalização e universalização como princípios organizadores das intervenções públicas, como se fossem excludentes. Mas, ao contrário, passa-se a examinar formas de conciliálos a partir dos conceitos de equidade ${ }^{24}$ e eficiência.

Isso seria conseguido por meio da garantia de certos serviços básicos, como educação e saúde, por exemplo, a amplos segmentos populacionais, associados a ações de transferência de renda e inclusão produtiva com acesso ao crédito. A lógica que pauta o debate é a de que se todos que têm direitos a esses serviços conseguem acessá-los, então o foco nos grupos que "merecem" esses serviços não seria algo limitador, mas uma forma de cumprimento efetivo desses direitos, pois se o programa é destinado aos mais pobres, os esforços devem se voltar para delimitar com acuidade quem são esses beneficiários. Diante disso, a solução estaria no desenvolvimento de políticas de combate à pobreza (ou classificadas como uma dimensão não-contributiva da política social) que, por atingir a quase totalidade do público alvo pretendido, estariam trazendo um novo tipo de "universalismo". Assim, o foco muda da contraposição entre focalização e universalização como princípios organizadores da oferta de serviços públicos na área social, para examinar os caminhos pelos quais novas formas de compatibilização entre eles vem sendo construídas.

Diante disso, a pretensão hoje é universalizar um patamar mínimo de proteção para os segmentos identificados como mais pauperizados. Tal empreitada tem nos indicadores de pobreza sua principal fonte de apoio, pois mais do que referências, constroem universos artificiais que acabam por plasmar uma suposta área/foco de ação.

Com isso, cria-se um campo de força ideológico onde se nivela por baixo a proteção social do conjunto dos trabalhadores precarizados, pois a ideia de que "o que se pode medir é solucionável" parte de uma perspectiva de "saída" da pobreza pelo esforço individual.

Por meio do transformismo e da cooptação por políticas de alívio da pobreza direcionadas ao imenso contingente que compõe o exército industrial de reserva, atualmente mundializado, [ocorre] a celebração do novo individualismo e das medidas sociais focalizadas em micronichos. (LEHER, 2010).

Os indicadores de pobreza, a despeito da contribuição que trouxeram para nos fazer ver a dimensão abusiva de seu contraponto, a vertiginosa concentração e centralização de capital contribuíram para o deslocamento das causas do fenômeno, retirando do debate termos como exploração/ expropriação para fundamentar noções como as de exclusão/inclusão.

Atualmente, as lutas pela efetivação dos direitos sociais passam necessariamente por disputas simbólicas que fundamentam os critérios que servem de referências para construção de políticas públicas. Assim,

É preciso insistir nas batalhas simbólicas de efeitos verdadeiramente decisivos que são travadas nos ministérios, nos escritórios dos especialistas, nos meios de comunicação, etc., e mesmo entre os intelectuais, e cuja conclusão há várias décadas nos faz esquecer o impacto das políticas macroeconômicas, o questionamento da função redistributiva e protetora do Estado. (TISSOT, 2007, p. 31). 


\section{REFERÊNCIAS}

DORNELLES, Denise Freitas. Direitos humanos e pobreza na sociedade contemporânea: não há equação possível. Serviço Social e Realidade, Franca, v. 16, n. 2, p.195-221, 2007.

GUIMARÃES, José Ribeiro Soares; JANNUZZI, Paulo de Martino. Indicadores sintéticos no processo de formulação e avaliação de Políticas Públicas: limites e legitimidades. In: ENCONTRO NACIONAL DE ESTUDOS POPULACIONAIS, 14, 2004, Caxambu, ANAIS... Caxambu: ABEP, 2004. Disponível em: <HTTP://www.abep.nepo.unicamp. br/site_eventos_abep/PDF/ABEP2004_296.pdf>. Acesso em: 3 jan 2011.

JANNUZZI, Paulo de Martino. Considerações sobre o uso, mau uso e abuso dos indicadores sociais na formulação e avaliação de Políticas Públicas Municipais. Revista de Administração Pública, Rio de Janeiro, v. 1, n. 36, p. 51-72, jan./fev. 2002. Disponível em: <http://app.ebape.fgv.br/academico/ asp/dsp_rap_artigos.asp?cd_edi=14>. Acesso em: 3 jan. 2011.

Indicadores para diagnóstico, monitoramento e avaliação de programas sociais no brasil. Revista do Serviço Público. Brasília, DF, v. 2, n. 2, p.137-160, abr./jun. 2005.

Indicadores Sociais no Brasil: conceitos, fonte de dados e aplicações. 2. ed. Campinas: Alínea, 2003.

LEHER, Roberto. Prefácio do livro: uma penetrante perspectiva teórica para compreender como os dominantes dominam. In: NEVES, Lucia Maria Wanderley (Org.). A direita para o social e a esquerda para o capital: intelectuais da nova pedagogia da hegemonia no Brasil. São Paulo: Xamã, 2010.

MAURIEL, Ana Paula Ornellas. Capitalismo, políticas sociais e combate à pobreza. ljuí: Unijuí, 2011.

Sonho e realidade na política social do governo FHC: um estudo sobre a Comunidade Solidária. 2000. 229 f. Dissertação (Mestrado em Serviço Social) - Escola de Serviço Social, Universidade Federal do Rio de Janeiro, Rio de Janeiro, 2000.

NARBONDO, Pedro. Reflexiones criticas sobre El Universalismo Basico. Revista Uruguaia de Ciência Política, Montevideo, n.15, p.151-172, 2006.
PEREIRA, Camila Potyara; AMORIM, Alvaro André Santarém. Pobreza no Brasil e América Latina: concepções restritas sobre realidades complexas. Argumentum, Vitória, v. 2, n. 2, p. 132-148, jul./dez. 2010.

PROGRAMA DAS NAÇÕES UNIDAS PARA O DESENVOLVIMENTO. Relatório do Desenvolvimento Humano 2010. Disponível em:<http://www.pnud.org.br/arquivos/rdh/rdh2010/ hdr_2010_pt_complete.pdf>. Acesso em: 3 jan. 2011.

Relatório do Desenvolvimento Humano 2000. Disponível em:<http://hdr.undp.org/en/reports/ global/hdr2000/>. Acesso em: 3 jan. 2011.

SANTAGADA, Salvatore. Indicadores sociais: uma primeira abordagem social e histórica. Pensamento Plural, Pelotas, n. 1, p. 113-142, jul./dez. 2007.

SEN, Amartya Kumar. Desenvolvimento como liberdade. São Paulo: Companhia das Letras, 2000.

Temas-chave do século XXI. In:

KLIKSBERG, Bernardo. As pessoas em primeiro lugar: a ética do desenvolvimento e os problemas do mundo globalizado. São Paulo: Companhia das Letras, 2010.

SOARES, Laura Tavares. O controle sobre os pobres e a hipocrisia das elites. Rio de Janeiro: Laboratório de Políticas Públicas, 2004. Disponível em <www.outrobrasil.net>. Acesso em: 3 jan. 2011.

SOUZA, José Moreira; CARNEIRO, Ricardo. Universalismo e focalização na política de atenção à pessoa com deficiência. Saúde e Sociedade, São Paulo, v.16, n.3, p. 69-84, 2007

TELLES, Vera da Silva. Indicadores Sociais entre objetividade e subjetividade. 2003. Estratos do texto apresentado por Vera Telles no Seminário Internacional sobre Indicadores Sociais para Inclusão Social - Núcleo de Estudos e Pesquisa em Seguridade e Assistência Social do Programa de Estudos Pós-Graduados da PUC-SP, em 15 e 16 de maio de 2003. Disponível em:<http://www.dhnet.org. br>. Acesso em: 10 out. 2010.

TISSOT, Sylvie. Ainvenção dos bairros problemáticos. Le Monde Diplomatique Brasil, São Paulo, ano 1, n. 3, out. 2007.

UL HAQ, Mahbub. Reflections on Human Development. New York: Oxford University Press, 1995. 
VIANNA, Maria Lucia Teixeira Werneck (Org.). A americanização (perversa) da seguridade social no Brasil. Rio de Janeiro: Revan, 1998.

A previdência social (e não só ela) em questão: notas aditivas à reflexão de Rosa Marques, Àquilas Mendes e Camila Ugino. Argumentum, Vitória, v. 2, n. 1, p. 31-40, jan./jun. 2010.

Notas:

1 O primeiro "Mapa da Fome" foi formulado a partir da incorporação de dados dos Censos Demográficos de 1980 e 1991 e da PNAD de 1990, e adotando a metodologia desenvolvida pela CEPAL - e em um trabalho redigido pelo IBGE, a partir do "Índice de Condições de Sobrevivência de crianças de 0 a 6", da UNICEF. Esses eram os dois únicos estudos que tinham informações por municípios, apresentando índices e ranking (MAURIEL, 2000).

2 A noção de "universalismo básico" tem ganhado espaço crescente na agenda de debate do Banco Interamericano de Desenvolvimento (BID) sobre direitos sociais na América Latina, pois permitiria a melhor utilização do gasto público social, concentrando-o, na etapa inicial, na universalização de prestações pecuniárias básicas para depois avançar para outros serviços (NARBONDO, 2006).

3 GILLIE, Alan. The origin of the poverty line. In: Economic History Review, vol. XLIX, $\mathrm{n}^{\circ} 4$, novembro de 1996.

4 Filantropo e empresário inglês B. Seebohm Rowntree, no seu estudo de 1902 sobre cidade, deu à pobreza uma definição mais precisa e propositadamente mais estreita, desenvolvendo um cálculo limite (nível de renda, custos, necessidades) a que chamou de "linha de pobreza".

5 "O termo pauperismo surgiu no século XIX na Inglaterra e significava o empobrecimento em massa da população não por falta de trabalho, mas justamente pelas péssimas condições de trabalho nas indústrias." (DORNELLES, 2007, p. 200)

6 Os trabalhadores rurais têm sido o segmento mais vulnerável à exploração, devido a um comportamento migratório em função das colheitas, sempre acabam fora do esquema de assistência pública, sem outra escolha senão aceitar baixos salários e condições de vida ditadas pelos fazendeiros locais. Essas são as principais barreiras estatutárias impostas pela própria estrutura do sistema para manter um segmento de trabalhadores mal pagos.

7 A metodologia do IDH vem modificando-se ao longo dos anos a fim de otimizar sua validade, o modo de comparação internacional dos seus valores finais e sua "compatibilidade longitudinal" (JANNUZZI, 2003, p. 8).

8 Este mede o grau de liberdade dos povos fazendo uso de critérios de convenções internacionais e da Declaração Universal dos Direitos Humanos. Foi elaborado em 1991.
9 Criado em 1992, congrega 5 dimensões: segurança, participação política, oportunidades iguais, liberdade de expressão e império das leis. Com isso, são feitos indicadores para verificar se os direitos estão sendo atendidos ou não.

10 Aponta diferenças entre esperança de vida, alfabetização, matrícula na escola e renda entre homens e mulheres. O índice foi gerado em 1995 e a substituição de deu em 1997.

11 Tem por objetivo mensurar o nível de participação das mulheres como mão de obra em cargos altos, na política e em profissões técnicas. Também teve sua elaboração em 1995 e substituição em 1997.

12 Esse novo indicador abriga o rendimento de encomendas externas e do suporte internacional para o desenvolvimento.

13 A criação de indicadores sintéticos fundamenta-se na ideia de que a combinação de diversos indicadores em um só reflete instantaneamente a realidade (JANNUZZI, 2002).

14 Já o Índice de Desenvolvimento Humano Ajustado à Desigualdade visa identificar as respectivas perdas no desenvolvimento humano como conseqüência de desigualdades nas dimensões de saúde, educação e rendimento. Foi estimado para 139 países e seu valor tende a revelar uma maior desigualdade em situações de países com IDH mais baixo. Em 2010, o Brasil obteve um valor de 0,509 nesse índice.

15 Neste foram incluídas as taxas de mortalidade maternal e a representação da figura feminina em parlamentos. Em suma, seu objetivo é mensurar os pontos negativos do desenvolvimento humano de discrepâncias sociais e econômicas acentuadas entre mulheres e homens, segundo informe do PNUD datado de 4 de novembro de 2010. Disponível no sítio: $<$ www.pnud.org.br>.

16 Assim consideradas por sofrer um determinado número de privações.

17 O IPH foi criado em 1997 como uma derivação do IDH para representar as dimensões de carência da vida humana, focando a amplitude da miséria nos países considerados pobres. Tais dimensões se traduzem por: percentual de pouca longevidade (falecimento antes dos 40 anos de idade), carência de educação básica (quantidade em pontos percentuais de adultos analfabetos) e a ausência do acesso aos recursos privados e públicos com três variáveis: porcentagem de indivíduos não tendo acesso aos serviços de saúde, água potável e a porcentagem de crianças de menos de 5 anos vítimas de desnutrição. É voltado para os países em desenvolvimento. Contudo, em 1998, esse índice foi adaptado aos países desenvolvidos como $\mathrm{IPH}-2$, com medidas mais adequadas ao contexto social e econômico de tais países.

18 Segundo essas dimensões, a esperança de vida no Brasil é de 72,9 anos; a média de anos de escolaridade é de 7,2 anos; e a expectativa dos anos de escolaridade é de 13,8 anos. 
19 Ou seja, sem as mudanças evidenciadas pelo Relatório de Desenvolvimento Humano de 2010.

20 As seis dimensões são as seguintes: ausência de vulnerabilidade, acesso ao conhecimento, acesso ao trabalho, disponibilidade de recursos, desenvolvimento infantil e condições habitacionais.

21 Para maiores informações sobre a discussão sobre desenvolvimento humano e governança ver MAURIEL, Ana Paula Ornellas. Notas críticas acerca do desenvolvimento humano na América Latina. Conjuntura Internacional e Serviço Social, Temporalis, Brasília, ano 9, n. 18, jul./dez. 2009.

22 Para mais informações sobre a noção de equidade que prevalece nas políticas de combate à pobreza ver Relatório de Desenvolvimento Mundial de 2006.

\section{Ana Paula Ornellas Mauriel}

\section{Socióloga}

Doutora em Ciências Sociais pela Universidade Estadual de Campinas (UNICAMP)

Professora Adjunta III da Universidade Federal Fluminense (UFF)

E-mail: apmauriel@gmail.com

\section{Caroline Beatriz Rangel Rais}

Assistente Social

Graduada em Serviço Social pela Universidade Federal Fluminense (UFF)

Assistente Social da Marinha do Brasil

E-mail: cbiarais@yahoo.com.br

\section{Universidade Federal Fluminense (UFF)}

Rua Miguel de Frias, 9, Icaraí, Niterói, RJ

CEP: $24220-900$

\section{Marinha do Brasil}

Esplanada dos Ministério, Bloco N, anexo A, Brasília, DF, CEP: 70055900 